\title{
Os correspondentes internacionais em zonas de conflito: ética, produção da notícia e teorias do jornalismo no ensino da profissão
}

\author{
Felipe Gomberg' \\ Camila Welikson²
}

\section{Resumo}

Este artigo discute o trabalho dos correspondentes internacionais em zonas de conflito, sua importância como exemplo de prática jornalística para a sala de aula e como é possível evidenciar a aplicação das teorias do jornalismo no dia a dia destes profissionais. Para isso, utilizamos entrevistas em profundidade, exclusivas, com correspondentes internacionais sobre a produção de notícia em ambientes de conflito.

Palavras-chave: Correspondentes internacionais. Teorias do jornalismo. Produção de notícia.

\section{Abstract}

This paper discusses the work of international correspondents in conflict zones, their importance as an example of journalistic practice to the classroom and how it is possible to highlight the application of journalism theories on the daily basis of these professionals. For this, we use exclusive interviews with international correspondents about the production of news in conflict environments.

Keywords: International correspondentes. Journalism Theory. News production.

\section{Introdução}

Uma situação de conflito é, indiscutivelmente, resultado de acontecimentos passados. Guerras e conflitos nascem a partir de uma complexa trama histórica e envolvem fatores cuja análise em profundidade não é possível dentro do espaço midiático.

1 Doutor em Comunicação pela Pontifícia Universidade Católica do Rio de Janeiro (PUCRio). Professor do Departamento de Comunicação Social da PUC-Rio. E-mail: gomberg@puc-rio.br.

2 Doutoranda em Comunicação pela Pontifícia Universidade Católica do Rio de Janeiro (PUC-Rio). Mestre em Estudo dos Media e do Jornalismo pela Universidade Nova de Lisboa. E-mail: camila@puc-rio.br.

Revista Pauta Geral-Estudos em Jornalismo, Ponta Grossa, vol. 6, n. 1, p. 22-38, Jan/Jun, 2019. 
Ainda assim, é inviável compreender o que se passa sem, ao menos, uma rápida contextualização. Os jornalistas que são enviados como correspondentes para zonas de conflito são obrigados a lidar com esta situação, o que inevitavelmente envolve questões éticas da profissão que são ensinadas e debatidas em sala de aula.

Quem ensina jornalismo sabe a prioridade que se dá historicamente às notícias quentes, ou seja, aos acontecimentos do dia a dia. Isto se evidencia na prática em relação aos correspondentes internacionais que necessitam identificar acontecimentos que diariamente atraiam a atenção do público. Já matérias mais elaboradas e elucidativas, que irão explorar questões históricas, ficam restritas a espaços segmentados na mídia. Os fatos contextualizados são mais comuns em documentários, reportagens de revista, programas de entrevistas ou de variedades.

Nesse contexto, a internet foi responsável por uma profunda alteração na forma de produzir matérias jornalísticas, uma vez que o espaço virtual possibilitou a extensão das notícias e, dessa forma, ficou viável contextualizar os acontecimentos. Agências de notícias e canais de notícias vinte e quatro horas, por exemplo, possuem em seus respectivos websites, páginas que abordam o lado histórico de conflitos. Dessa forma, a discussão sobre a contextualização ou não dos acontecimentos referentes a conflitos acaba por ser resolvida dentro da própria imprensa que estabelece espaços específicos para a elucidação de questões mais complexas e cabe, portanto, ao público, buscar a informação nos locais onde ela está disponível.

Patrick Charaudeau questiona se, atualmente, o excesso de informação não produz um efeito de saturação que afeta também os espaços próprios à complementação dos fatos, à contextualização.

\begin{abstract}
A notícia só tem licença para aparecer nos organismos de informação enquanto estiver inscrita numa atualidade que se renova pelo acréscimo de pelo menos um elemento novo; além do mais, é preciso que esse elemento novo seja portador de uma forte carga de inesperado para evitar o que as mídias mais teme: a saturação (...). Isso explica as dificuldades das mídias em dar conta do passado (...). O discurso das mídias se fundamenta no presente de atualidade, e é a partir desse ponto de referência absoluto que elas olham timidamente para ontem e para amanhã, sem poder dizer muita coisa a respeito. (CHARAUDEAU, 2006, p. 134)
\end{abstract}

O que é definido como notícia está diretamente associado à escolha de estratégias discursivas; é imprescindível, portanto, que os correspondentes possuam um saber Revista Pauta Geral-Estudos em Jornalismo, Ponta Grossa, vol. 6, n. 1, p. 22-38, Jan/Jun, 2019. 
reflexivo, ou seja, um saber que questione o próprio saber para que a imprensa consiga, cada vez mais, acertar na seleção das informações que são transmitidas para o público.

Os jornalistas e, no caso aqui apresentado, os correspondentes internacionais em zonas de conflito, devem estar cientes do compromisso e da responsabilidade moral como profissionais da comunicação. Devem, também, conhecer bem a ética jornalística e, munidos de todo conhecimento que Ihes foi ensinado, devem saber articular a teoria e a prática.

Este artigo discute o trabalho dos correspondentes internacionais em zonas de conflito, sua importância como exemplo de prática jornalística para a sala de aula e como é possível evidenciar a aplicação das teorias do jornalismo no dia a dia destes profissionais. Para isso, utilizamos entrevistas em profundidade realizadas com correspondentes internacionais (WELIKSON, 2008) sobre a produção de notícia em ambientes de conflito.

\section{Os correspondentes em zonas de conflito}

O trabalho do correspondente de guerra, além de gratificante, é um ofício que rende prestígio para o jornalista que o realiza. A experiência única e o reconhecimento são aspectos levados em consideração no momento de o jornalista aceitar realizar cobertura em regiões de conflito.

Entre os que se destacam nesse tipo de cobertura estão os jornalistas locais, ou seja, profissionais que nasceram ou vivem na região de conflito a ser coberta jornalisticamente. São comumente chamados para trabalhar em veículos de comunicação internacionais porque conhecem a língua local, estão inteirados das situações cotidianas, conhecem o conflito e a história da região, têm contatos dentro da imprensa local e, muitas vezes, contatos entre políticos e militares, o que contribui para a obtenção de informações para a produção da notícia. Como muitos trabalham também para a imprensa local, eles têm acesso aos furos jornalísticos.

Se por um lado representam um custo menor para as empresas de comunicação porque são residentes, não gerando as despesas adicionais de um enviado especial, é sempre maior a possibilidade de esses profissionais assumirem uma postura partidária. A produção de notícias é feita com base em um ponto de vista já formado e com influência da educação, religião, cultura e posição política do produtor do conteúdo. Mas é impensável alterar esta realidade. Este grupo de jornalistas é fundamental para fazer

Revista Pauta Geral-Estudos em Jornalismo, Ponta Grossa, vol. 6, n. 1, p. 22-38, Jan/Jun, 2019. 
funcionar a máquina midiática e é impossível modificar a forma como ele influencia, mesmo que sutilmente, a produção das notícias.

Um segundo grupo de jornalistas é formado por aqueles que decidem se mudar para uma região de conflito com o principal propósito de se tornar correspondente internacional. Neste caso, os jornalistas buscam, em primeiro lugar, atingir fins profissionais. Qualquer pessoa que aceite o desafio de viver em um ambiente de conflito sabe que este é um passo bastante significativo em sua carreira e os anos como correspondente proporcionam destaque no meio jornalístico, conhecimento, respeito e muito prestígio.

Geralmente, esses jornalistas passam por um crescimento em suas carreiras até conquistar uma vaga como correspondente de zona de conflito. Eles são convidados ou passam por um disputado processo de seleção e só então buscam se informar mais profundamente sobre o local para onde serão transferidos. Antes disso, são jornalistas que não têm como prioridade em suas vidas aquele determinado conflito e, geralmente, conhecem os problemas do local através dos próprios meios de comunicação.

O que diferencia este grupo do primeiro é o fato de a maioria dos jornalistas que opta por viver esta experiência ser, de um modo geral, ignorante do contexto histórico que envolve o conflito.

Temos, então, uma situação um tanto singular: jornalistas que já vivem em regiões de conflito e trabalham como correspondentes são bem informados, mas costumam sofrer influência ideológica; jornalistas que optam por este caminho simplesmente por questões profissionais são pouco informados e buscam se instruir mais profundamente apenas quando são escalados para o trabalho. Ainda assim, a chegada ao ambiente de conflito é surpreendente e as descobertas in loco são mais reveladoras do que horas de profunda pesquisa.

\section{O correspondente, a produção da notícia e as teorias do jornalismo}

Quem são os homens que explodem ônibus e restaurantes? Mártires ou terroristas? Quem são os soldados em uma guerra civil? Um exército de defesa ou um exército de rebeldes ocupantes? Difícil encontrar uma resposta única quando a forma de encarar os fatos nasce de realidades, mais que distintas, opostas. Não é apenas a opinião pessoal que influencia os jornalistas nesse tipo de decisão editorial que classifica os 
personagens dessas notícias. Na busca por um ponto de equilíbrio, os profissionais esbarram em outros fatores, entre eles, o ambiente de trabalho.

Uma das principais características do jornalismo contemporâneo é a celeridade da informação e a batalha contra o tempo e o espaço. Transformada em mercadoria, a notícia passa a ser um produto com data de expiração e, fora do seu prazo de validade, não tem valor no mercado.

O tempo é um dos principais fatores responsáveis pela transformação de um acontecimento em notícia. De acordo com os estudos de Philip Schlesinger (1977), o fato de a notícia ser perecível cria uma nova estrutura produtiva, onde o imediatismo passa a ser um elemento chave na criação das reportagens midiáticas e o tempo torna-se parte indispensável do processo de formação e transmissão da informação assim como valores já enraizados no jornalismo, entre eles, a objetividade e o profissionalismo.

O deadline, ou o prazo de entrega das reportagens, funciona como um chefe malhumorado que pressiona o jornalista que está em campo e dita o ritmo de trabalho. Como afirma Schlesinger, "o curso segue um regular ciclo diário, cuja cadência é pontuada por deadlines. Estes e os inexoráveis ponteiros do cronômetro são dois dos mais potentes símbolos na cultura profissional do jornalista". (SCHLESINGER apud TRAQUINA, 1999, p. 179)

Há, ainda, dois fatores determinantes no trabalho jornalístico: o espaço e a hierarquia. Apesar de a Internet, atualmente, permitir a criação de mais e mais espaço, além de ocupar, muitas vezes, o papel do gatekeeper, ainda é necessário haver uma regra de seleção que determine o que se torna notícia e o que entra para o hall de fatos midiaticamente esquecidos.

Ao ensinar jornalismo, estas questões - tempo, espaço e hierarquia - são bastante discutidas e o debate gira em torno da importância de lidar com as pressões da profissão sem perder de vista um importante objetivo: informar com objetividade.

Esta é, aliás, a conclusão de uma análise comparativa dos códigos de ética em diferentes continentes realizada por Kai Hafez (2002). Em seu estudo, o autor expõe a ideia de que no âmbito teórico, a verdade, a exatidão e a objetividade são valores éticos universais. Hafez afirma que as normas jornalísticas variam de acordo com a História e a cultura de cada país. Tomamos como exemplo, locais onde, no passado, houve repressão e intimidação, tanto por parte do Estado como por parte de grupos de guerrilha. Nestes casos, a liberdade de expressão é considerada prioridade nos códigos deontológicos. É o 
que ocorre na Ásia, na África e na América Latina, onde os limites para o debate público são enraizados em valores sociais e normas profissionais que não podem ser controladas pelo Estado. Entretanto, em todos os códigos, a cobertura imparcial forma a essência da profissão. A imparcialidade e objetividade são, portanto, essenciais para quem decide seguir esta carreira.

Faz parte do papel do correspondente internacional pôr em prática o que é definido pela deontologia e pelas teorias jornalísticas. Por outro lado, o que se vê é uma constante acusação de parcialidade que recai sobre a imprensa. É hoje um lugar comum, dentro do espaço público, afirmar que a imprensa falta à verdade e é parcial.

A complexidade da narrativa jornalística, neste caso em especial, da narrativa de conflitos, leva os profissionais da imprensa a lidar constantemente com o desafio de buscar a objetividade para assim, apresentar o mais alto padrão profissional possível, como assegura o correspondente Henrique Cymermann:

\footnotetext{
A objetividade é uma utopia (...), ser uma utopia não significa que não devemos tentar nos aproximar dela. No fundo é impossível, nunca vamos chegar a ela. Mas não posso esquecer de ser honesto, o que significa voltar aos princípios básicos do jornalismo. (CYMERMANN. In: WELIKSON, 2008, p. 111)
}

Alcançar tal utopia é apenas um dos desafios dos jornalistas, mas na tentativa de alcançar este objetivo, tarefa árdua e complexa, surgem situações que levam a críticas por parte daqueles que recebem as informações noticiosas. Porém, há outros obstáculos, principalmente para os jornalistas que trabalham em zonas de conflito e ambientes de guerra.

O primeiro obstáculo são as decisões editoriais concernentes à produção da notícia. O que é um acontecimento noticioso numa zona de conflito? O que deve ser reportado e o que deve ser deixado de lado? Como já vimos, é difícil manter a desejável neutralidade num ambiente onde impera uma profunda radicalização no plano das crenças e das práticas políticas. Tornou-se lugar comum acusar jornalistas de parcialidade e falta com a verdade, simplesmente por haver notícias contrárias a interesses individuais.

Mas há que se considerar, ainda, que correspondentes internacionais são funcionários de empresas e devem seguir seu compasso, seja a empresa um jornal, uma revista, uma estação de rádio, um site ou um canal de televisão.

Revista Pauta Geral-Estudos em Jornalismo, Ponta Grossa, vol. 6, n. 1, p. 22-38, Jan/Jun, 2019. 
Como em qualquer lugar do mundo, as diferentes empresas de comunicação, maiores ou menores, possuem internacionalmente maior força ou não. A política interna de uma redação e da empresa, de forma mais geral, é determinante para o posicionamento dos profissionais que atuam como correspondentes. A postura e a forma de pensamento variam de acordo com o local de trabalho.

Este enfoque é muito criteriosamente feito por Warren Breed em sua Teoria Organizacional. $\mathrm{Na}$ sua análise, o autor dá um destaque especial aos constrangimentos externos sobre a atividade profissional.

Para Breed (apud TRAQUINA, 1999), não existe apenas uma questão subjetiva na escolha das notícias. Há também uma conformação com as normas e a política editorial da organização em que se trabalha. Breed (apud TRAQUINA, 1999) afirma que a organização influencia o processo de decisão e de ação do jornalista. De acordo com esta teoria, as normas e a política da empresa assumem um peso significativo, maior até do que as próprias escolhas e opiniões pessoais.

Obedecer à política organizacional não é uma ordem estabelecida abertamente, até porque vai contra os princípios básicos do jornalismo. Mas acaba ficando implícito no cotidiano das organizações que levam os profissionais a agir conforme a "vontade da casa".

Os sentimentos de respeito, admiração e estima para com os superiores também podem influenciar a forma como o jornalista trabalha. Ter a sensação de dever com aqueles que o receberam e o ensinaram cria uma espécie de constrangimento. Mas não é só. As aspirações pessoais, a vontade de crescer profissionalmente, ganhar notoriedade, ter o trabalho reconhecido e valorizado, todos estes pontos levam os jornalistas a ter um certo "respeito" com as ideologias organizacionais. Ir contra elas ameaça a possibilidade de crescimento profissional.

Existem formas de burlar as regras estabelecidas na organização. A própria liberdade jornalística o permite, como fica claro com a declaração de Juan Miguel Muñoz, correspondente do jornal espanhol El Pais, ao afirmar que "nos artigos, não posso colocar o que penso, mas enfoco de uma maneira que deixa claro como vejo o assunto" (WELIKSON, 2008, p. 39).

A relação entre a empresa e o profissional segue, de certa forma, harmoniosamente e as pressões sociais existentes são, em alguns aspectos, atenuadas e assim o sistema funciona. Ao contrário do que defende a Teoria do Gatekeeper, para Jan/Jun, 2019. 
Breed, na teoria organizacional, as ideias pessoais, as crenças e os valores subjetivos ficam apagados, são anulados diante da máquina organizacional.

Nos anos de 1970 surgiram duas novas teorias: estruturalista e interacionista. Estas novas hipóteses teóricas reconhecem que existem constrangimentos organizacionais que influenciam a produção noticiosa, mas contestam a visão de que o jornalista é um mero observador sem voz ativa. Por fim, defendem a ideia de que os jornalistas são atores participantes na construção da realidade.

Há uma singularidade no caso dos jornalistas que trabalham em ambientes de conflito. Eles têm determinada autonomia para expressar seus pontos de vista porque os editores localizados nas sedes das organizações não têm o conhecimento necessário para arguir com seus correspondentes em relação a este tema específico. Além disso, como afirma Patrick Charaudeau, não existe maneira de capturar a realidade empírica sem que haja a passagem pelo filtro do ponto de vista particular. Tal ponto de vista constrói um determinado objeto particular que passa a ser visto como fragmento do real. $\mathrm{O}$ autor afirma que:

Sempre que tentamos dar conta da realidade empírica, estamos às voltas com um real construído, e não com a própria realidade. Defender a ideia de que existe uma realidade ontológica oculta e que, para desvelá-la, é necessário fazer explodir falsas aparências, seria reviver um positivismo de falsa qualidade. (CHARAUDEAU, 2006, p. 131)

Percebemos, então, que o poder de decisão do que será noticiado e como será noticiado não está centrado apenas em uma figura. Mesmo os jornalistas com menos poder podem acabar por influenciar nas decisões da organização, e não só eles, afinal, não é apenas na mão de uma única pessoa que ocorre o filtro da notícia. A decisão começa na reunião de pauta, prossegue na forma como a matéria é produzida, quem é entrevistado, quais as perguntas feitas, que imagens são registadas, como é formulada e editada a matéria.

Neste processo, filtros acontecem e determinadas informações são eliminadas. Portanto, em todo o momento, todos os profissionais que participam da produção da notícia funcionam como porteiros (gatekeepers) que decidem o que entra e o que sai da história, mas boa parte deste filtro acontece no dia a dia da cobertura noticiosa e está, em grande parte, nas mãos dos correspondentes internacionais.

Revista Pauta Geral-Estudos em Jornalismo, Ponta Grossa, vol. 6, n. 1, p. 22-38, Jan/Jun, 2019. 


\section{Os correspondentes e o dia a dia da cobertura}

Ter a experiência de viver e trabalhar como jornalista em ambiente de conflito é aprender sobre o local que é palco dos importantes acontecimentos noticiosos e que marcam o desenrolar da História, tornando-se um relevante desafio tanto profissional quanto pessoalmente.

Após um período de adaptação, é possível que o correspondente se torne frio diante dos acontecimentos de guerra. José Rodrigues Santos (2001) os qualifica como voyeurs que transformam o conflito em objeto de valor mercantil. São indivíduos que aprendem a utilizar os acontecimentos em notícias vendáveis e rentáveis. Passa a ser mecânico o ato de registrar os fatos de forma puramente narrativa, como se houvesse uma separação entre a pessoa humana que presencia o horror da guerra e o profissional que a relata para ganhar a vida.

Este é também um mecanismo de defesa de quem convive com as atrocidades de uma guerra e um escudo contra a sensibilidade e o medo:

O correspondente tende, nestas circunstâncias, a esquecer que faz parte daquele real e que também ele pode ser atingido. Em vez disso, olha para o acontecimento como se se tratasse de algo que está à espera de ser narrado, e que ele, repórter, é um voyeur autônomo, inatingível e desligado daquela ação. (SANTOS, 2001, p. 939)

Há, também, a possibilidade dos correspondentes se envolverem profundamente com o acontecimento que eles deveriam apenas narrar, principalmente quando existe uma ligação mais contígua com indivíduos e suas histórias particulares. O jornalista Henrique Cymermann afirma que "viver o dia a dia da notícia fez chegar a ele o terror e a miséria, mas também a grandeza humana em situações difíceis" (CYMERMAN, 2005, p. 25). Susan Moeller defende esta possibilidade e descreve como funciona o processo de envolvimento de um jornalista com determinada causa:

Correspondentes internacionais simplesmente reportam genocídios e os chamam de holocaustos porque eles são humanos. São eles que sufocam com o cheiro da morte, silenciam com a visão de crianças deitadas e cortadas ao meio. Eles podem tentar e desassociar eles mesmos daquilo que testemunham - mesmo que seja somente para chegar até o fim do dia - mas os horrores os perseguem. Então, eles se tornam ativistas. (MOELLER, 1997, p. 237)

Revista Pauta Geral-Estudos em Jornalismo, Ponta Grossa, vol. 6, n. 1, p. 22-38, Jan/Jun, 2019. 
Para Susan Moeller, muitos correspondentes de guerra tornam-se parciais em relação aos eventos que cobrem. Na sua opinião, em conflitos, não existem partes neutras e, ao cobrir genocídios, há sempre um dos lados que assume o papel de vilão e outro de mocinho. Dentro deste contexto, na visão da autora, os jornalistas assumem o papel de advogados que estimulam a cobertura midiática com o intuito de melhorar as condições dos sobreviventes. Moeller utiliza depoimentos de correspondentes que afirmam ser impossível permanecer indiferente diante de situações de guerra. Dentre eles, um cinegrafista da rede BBC que diz ter perdido seu otimismo e garante que nada o teria preparado para o que ele testemunhou em Ruanda.

O confronto com uma diferente realidade econômica, cultural e social transforma definitivamente o modo de pensar dos correspondentes. Ainda assim, eles continuam a carregar suas próprias bases educacionais, culturais e sociais e isso tem uma enorme importância na forma como os acontecimentos são relatados.

Como já vimos, de forma geral, os jornalistas que conhecem o assunto profundamente e sabem contextualizar o conflito estão geralmente influenciados por um lado ou outro e, portanto, assumem uma postura parcial, mesmo que inconscientemente. $\mathrm{E}$ o que ocorre, então, com os jornalistas que chegam nas regiões de conflito com interesses puramente profissionais? Daniela Kresch, correspondente internacional com passagens pela Folha de S. Paulo, Estadão, GloboNews, Rádio França Internacional e pela rádio portuguesa TSF, acredita que estes também são parciais:

A neutralidade é impedida no caso das pessoas que não conhecem nada e chegam aqui de paraquedas, pela ignorância. Você não consegue ser neutro se é ignorante num assunto. Mas, por outro lado, uma pessoa que conhece tudo do assunto e tem uma posição, também vai ser difícil para ela ser neutra. A neutralidade é uma utopia que pode ser esquecida. (KRESCH. In: WELIKSON, 2008, p. 36)

Se em alguns casos, ser imparcial é utópico, em muitos outros casos, a busca por esta imparcialidade e pela objetividade - parte da ética profissional - torna-se um desafio constante. Correspondentes que cobrem conflitos questionam como colocar em prática o que é ensinado nas universidades de jornalismo. Uma alternativa é ir além de informar os 
acontecimentos atuais e contextualizar o conflito, eliminando ao máximo a chamada ahistoricidade ${ }^{3}$ do jornalismo.

Não é o caso de Claudio Pagliara. O correspondente do canal italiano RAI acredita que sua função é apenas informar os acontecimentos atuais:

Não temos que escrever um livro político sobre o conflito. Contamos histórias, fatos. Para ter uma ideia completa do problema é preciso tempo. Não se pode pensar e esperar que em toda a história tenha uma explicação do conflito, isto não é jornalismo. (...) Não vou explicar cada razão por trás de cada facto ou explicar o passado. (PAGLIARA. In: WELIKSON, 2008, P. 59)

Jo Floto, editor da rede inglesa BBC, discorda de Pagliara. Ela defende a importância da contextualização e afirma que sua empresa propõe soluções para informar o seu público da forma mais abrangente possível:

Se você olhar para trás e tentar ver o contexto das notícias, você se perde, o difícil é contextualizar toda a questão que envolve a notícia no pouco tempo que se tem. Uma pessoa que não acompanha a notícia diariamente nem sempre consegue captar todo o contexto porque não temos espaço para isso. Algumas pessoas acham que as matérias não estão completas. Portanto, colocamos todo o contexto do que se passa no nosso website. (PAGLIARA. In: WELIKSON, 2008, p. 60)

A cobrança pela imparcialidade gera uma pressão grande nos correspondentes. $O$ jornalista espanhol Domenec Subirá i Quintá questiona se esta espécie de imposição faz sentido:

Perguntamos o que é ser imparcial, o que significa isso? Perguntar a um e perguntar a outro e um diz isso e o outro diz aquilo e pronto? Isto é ser imparcial? Isto então não é ser jornalista, é pegar declarações de um e de outro. Na minha opinião, o jornalista tem que constatar o ocorrido e tentar demonstrar quem dos dois tem mais ou menos razão (...) O que tenho que fazer é contar o que sei que se passa e não somente o que escutei das fontes. Para isso, colocava uma secretária muito boa a tomar notas e a colocava a anotar exatamente o que disseram uns e outros. Quando se fala de ser imparcial é como se quisessem que fizéssemos só isso. (SUBIRÁ I QUINTÁ. In: WELIKSON, 2008, P. 30)

3 A avalanche de acontecimentos que chegam às redações e a efemeridade das informações midiáticas obrigam os profissionais de jornalismo a criar uma rotatividade noticiosa frequente onde um novo assunto elimina o anterior, o que o obriga a deixar de lado o passado, portanto, o contexto histórico, o que Charaudeau denomina como uma característica do jornalismo, a a-historicidade.

Revista Pauta Geral-Estudos em Jornalismo, Ponta Grossa, vol. 6, n. 1, p. 22-38, Jan/Jun, 2019. 
Outra preocupação dos correspondentes internacionais em regiões de conflito está relacionada com as informações provenientes de fontes, seja, elas institucionais (órgãos representativos do Estado, organizações sociais como partidos e sindicatos, assim como os políticos) ou não institucionais.

As fontes institucionais estão claramente de um lado do conflito e defendem sua versão dos acontecimentos. Se por um lado, estas fontes são parciais, por outro lado, são confiáveis na medida em que podem ser usadas pela imprensa de forma a dar credibilidade à informação.

Entre as fontes não oficiais, o risco de parcialidade é ainda maior. Pessoas envolvidas no conflito estão cientes de que jornalistas são uma força que pode moldar a opinião pública e, portanto, os usam como "arma" a seu favor. Se por um lado, os correspondentes têm consciência de que cada fonte se esforça para que a sua versão dos fatos prevaleça, por outro lado, eles também têm consciência de que fontes não institucionais podem enriquecer bastante as matérias jornalísticas.

Este é um problema que todos os jornalistas que trabalham como correspondentes em zonas de conflito enfrentam, como esclarece Jacque Shoen, que trabalhou para o jornal Palestine Times:

Qualquer fonte oficial é tendenciosa, sempre tem seus próprios interesses. Na guerra do Líbano, para checar as informações, falava com várias fontes, seis ou sete, e cada uma delas tinha números diferentes para dar. E esses são fatos, as pessoas deveriam ter dados, mas cada um tinha números diferentes. (SHOEN. In: WELIKSON, 2008, p. 74)

Na opinião de Jo Floto é preciso estar muito atento a tudo o que é dito e quais os interesses por trás das palavras, principalmente quando são as fontes que buscam os jornalistas para contar uma história:

É preciso sempre dar um passo atrás e pensar porque esta informação chegou a mim e porque esta pessoa está me procurando e me contando isso. É preciso lembrar que as fontes muitas vezes estão envolvidas nas histórias e têm seus próprios interesses. (FLOTO. In: WELIKSON, 2008, p. 15)

Para Yael Lavie, da rede Sky News, existe uma dificuldade em relação às fontes, mas todos os correspondentes aprendem a lidar com elas:

Revista Pauta Geral-Estudos em Jornalismo, Ponta Grossa, vol. 6, n. 1, p. 22-38, Jan/Jun, 2019. 
A informação é fácil de obter porque todo mundo vê tudo, dos dois lados, você sempre tem as duas versões, os dois pontos de vista. Depois de passar um ou dois anos aqui você descobre que todos têm uma agenda, todos. Não é simplesmente ter duas fontes, mas saber quem são essas fontes, de onde elas vêm. No final, a informação está disponível, a agenda não é necessariamente mentirosa. (LAVIE. In: WELIKSON, 2008, p. 25)

Há, ainda, a possibilidade de usar como fonte informações das agências de notícias. Esta, aliás, é uma prática rotineira por questões de viabilidade, como explica Daniela Kresch:

Fica difícil competir com grandes meios de comunicação e agências de notícias. Eles são muito mais rápidos do que eu jamais poderia ser, eles são grandes, com muita gente e imediatamente quando acontece alguma coisa, eles, em questão de segundos, já têm a reação. Eles têm as informações de um fato em segundos e de várias fontes porque as agências falam com várias fontes, então, acaba não tendo a necessidade - no caso de hard news - de checar. Eu raramente, uma ou duas vezes, desde que cheguei aqui, liguei para alguém para checar alguma coisa. Em geral, vejo se as agências publicaram e vejo a notícia pela televisão e rádio locais. (KRESCH. In: WELIKSON, 2008, p. 68)

Mais do que uma questão de viabilidade, noticiar o que publicam as agências de notícias é uma questão de sobrevivência dos correspondentes internacionais. Juan Miguel Muñoz, que trabalhou para o jornal El Pais, diz, em entrevista a Welikson (2008), depender das agências e que esta é a realidade do trabalho do correspondente. Até entre as agências, existe a necessidade de publicar o que a concorrente noticiou. Daniela Brik, da agência de notícias espanhola EFE, descreve este fenômeno:

\begin{abstract}
Quando uma grande agência dá uma notícia, temos que dar também, mesmo sem ter tempo de checar. As outras agências de informação também são fontes e temos que dar a notícia citando-as como fonte. A competição com as outras agências também atrapalha, não só a velocidade. Madrid, às vezes, nos telefona e diz que viu em outras agências informações que nós não demos e querem saber o porquê. Não resta outra opção, temos que dar. (BRIK. In: WELIKSON, 2008, p. 67)
\end{abstract}

Portanto, as agências de notícias criam uma espécie de "ditadura", onde informações noticiosas são selecionadas a partir do que as agências produzem. As notícias publicadas dependem, portanto, do trabalho das agências e nenhum meio de comunicação ousa fugir desta "ditadura" para não correr o risco de perder credibilidade ao

Revista Pauta Geral-Estudos em Jornalismo, Ponta Grossa, vol. 6, n. 1, p. 22-38, Jan/Jun, 2019. 
deixar de publicar notícias que são publicadas por seus concorrentes. Faz parte do trabalho de cada correspondente estar atento à imprensa: ler, ver e ouvir o que os outros correspondentes estão a comunicar e ter a certeza de que está a falar sobre os mesmos assuntos.

Há, no dia a dia da cobertura jornalística em ambientes de conflito, inúmeras situações que podem levar a um trabalho que foge à ética aprendida nas salas de aula. Resta ao correspondente internacional a tarefa nada simples de conciliar a teoria aprendida nos cursos de jornalismo com o cotidiano de um profissional que enfrenta várias dificuldades, mas mantém o compromisso de reportar conflito complexos.

Quanto à sala de aula, o docente pode e deve usar a experiência do correspondente para abordar aspectos relevantes da profissão. Leonel Aguiar diz que é importante debater os conceitos advindos da Teoria do Jornalismo:

Os professores que ensinam as técnicas de redação jornalística sempre
se defrontam com esta complexidade teórica e, muitas vezes, um modo
de solucionar as demandas pedagógicas nas práticas laboratoriais acaba
sendo suas experiências profissionais. Por mais que o fazer jornalístico
possibilite ao profissional ter uma noção pragmática do que é notícia,
entendemos que conceitos advindos da Teoria do Jornalismo - em
especial, da abordagem do newsmaking - podem trazer contribuições
relevantes para o ensino das técnicas jornalísticas, particularmente nas
disciplinas iniciais do ciclo profissional. (AGUIAR, 2007, p. 3 e 4)

De fato, é indispensável discutir teoria nos cursos de jornalismo. No entanto, é possível e enriquecedor discuti-la aproveitando-se do que se vê na prática; neste caso, na vivência dos correspondentes internacionais.

\section{Conclusão}

Ainda hoje, existe uma idealização do jornalista como a de alguém capaz de reproduzir a realidade através da notícia. ${ }^{4}$ Para Felipe Pena, isto se dá porque crê-se em um profissional do jornalismo capaz de assumir imparcialidade diante de quaisquer acontecimentos:

\footnotetext{
${ }^{4}$ Esta é a ideia por trás da Teoria do Espelho, que defende ser a imprensa um espelho da realidade. Portanto, de acordo com esta teoria, as notícias seriam um reflexo do que é real, como se os relatos publicados por profissionais desta área fossem uma reprodução fiel dos fatos.
}

Revista Pauta Geral-Estudos em Jornalismo, Ponta Grossa, vol. 6, n. 1, p. 22-38, Jan/Jun, 2019. 
Isso acontece porque ela [comunidade jornalística] dá legitimidade e credibilidade aos jornalistas, tratando-os como imparciais, limitados por procedimentos profissionais e dotados de um saber de narração baseado em método científico que garante 0 relato objetivo dos fatos. (PENA, 2008, p.126)

Se a imparcialidade é uma meta, como alcançá-la estando em meio a um conflito, cujos acontecimentos abalam profundamente seus protagonistas e suas testemunhas?

$\mathrm{Na}$ cobertura midiática de guerras, existe uma linha bastante tênue entre o relato frio e distanciado dos acontecimentos e o envolvimento com a causa a ser reportada. Ou o jornalista se coloca numa posição de distanciamento face às partes em conflito, o que Ihe permite manter o distanciamento analítico indispensável a um jornalismo comprometido com a verdade; ou opta por envolver-se, racional e afetivamente, fazendo sua a causa de uma das partes em conflito.

É preciso ter bastante atenção com o posicionamento e a forma como este posicionamento é exposto, mesmo nos casos em que seja inevitável assumir uma posição. É o que explica o juiz espanhol Baltasar Garzón Real:

Certamente, diante de um atentado terrorista, nem o juiz, nem o jornalista fazem seu trabalho com comodidade e portanto, não com insensibilidade. A dor causada pela injustiça se reflete na imagem e em textos que são produzidos. Em nenhum caso, são documentos frios, sem argumentos de denúncia de uma situação absurda e delirante que cobra, de forma sistemática, vidas de inocentes. (REAL apud CYMERMANN, 2005, p. 25)

Qualquer que seja o discurso teórico relacionado com a objetividade, este estará distante da realidade e das condições práticas da vida jornalística. Entretanto, é necessário fazer um esforço para manter a ética no cotidiano profissional. Isto pode ser possível se dispensarmos o discurso positivista, uma vez que ele é inviável, e adotarmos a objetividade subjetividade como uma ferramenta a mais para o esclarecimento do público, como sugere o princípio II da declaração da UNESCO de 1983:

A tarefa primordial do jornalista consiste em servir o direito do povo a uma informação verdadeira e autêntica através de uma ligação honesta à realidade objetiva, colocando conscientemente os fatos no seu contexto adequado, evidenciando as suas relações essenciais, sem levar a distorções, desenvolvendo a capacidade criativa do jornalista, de forma a que o público receba um material, em que a origem, a natureza e a

Revista Pauta Geral-Estudos em Jornalismo, Ponta Grossa, vol. 6, n. 1, p. 22-38, Jan/Jun, 2019. 
essência dos acontecimentos, processos e situações, sejam compreendidos de modo tão objetivo quanto possível. ${ }^{5}$

Portanto, saber associar a busca por objetividade com a realidade do cotidiano da imprensa que comporta inequivocamente a subjetividade é mais do que o papel do jornalista, é o seu desafio. É o que poderá garantir a sua credibilidade diante do público e também, irá garantir a realização de um trabalho honesto e íntegro.

\section{Referências}

CHARAUDEAU, Patrick. Discurso das mídias. São Paulo: Editora Contexto, 2006.

AGUIAR, Leonel. Ensinar as práticas a partir da Teoria do Jornalismo: uma proposta pedagógica. Rebej (Brasília), v. I, p. 3-29, 2007.

BRIK, Daniela. Entrevista concedida a Camila Welikson, 2008.

CYMERMAN, Henrique. Voces desde el centro del mundo. El conflicto entre Árabes e Israelíes contado por sus protagonistas. Madrid: Temas de Hoy, 2005.

FLOTO, Jo. Entrevista concedida a Camila Welikson, 2008.

HAFEZ, Kai. Journalism ethics revisited: a comparison of ethics codes in Europe, North Africa, the Middle East and Muslim Asia. In: Political Communication. Londres: Taylor \& Francis Group, 2002, p. 225-250.

KRESCH, Daniela. Entrevista concedida a Camila Welikson, 2008.

LAVIE, Yael. Entrevista concedida a Camila Welikson, 2008.

MOELLER, Susan D. "A hierarchy of innocence. The media's use of children in telling of international News". In: The Harvard International Journal of Press/Politics. Nova York: Sage Publications, 2002, p. 36-56.

Compassion Fatigue: How the Media sell Disease, Famine, War and Death. Nova York: Routledge, 1999.

MUÑOZ, Juan Miguel. Entrevista concedida a Camila Welikson, 2008.

PAGLIARA, Claudio. Entrevista concedida a Camila Welikson, 2008.

PENA, Felipe. Teoria do jornalismo. São Paulo: Contexto, 2008.

${ }^{5}$ Emitido pela quarta reunião consultiva de organizações internacionais e regionais de jornalistas profissionais, que teve lugar em Praga e Paris em 1983.

Revista Pauta Geral-Estudos em Jornalismo, Ponta Grossa, vol. 6, n. 1, p. 22-38, Jan/Jun, 2019. 
SANTOS, José Rodrigues. O correspondente de guerra, o discurso jornalístico e a história. Para uma análise da reportagem de guerra em Portugal no século XX. Tese de Doutorado em Comunicação Social. Lisboa: Universidade Nova de Lisboa. 2001.

SCHLESINGER, Philip (1977), "Os jornalistas e a sua máquina do tempo", in Nelson Traquina (1999), Jornalismo: Questões, Teorias e 'Estórias', Lisboa, Vega, pp. 177190.

SHOEN, Jacque. Entrevista concedida a Camila Welikson, 2008.

SUBIRÁ I QUINTÁ, Domenec. Entrevista concedida a Camila Welikson, 2008.

TRAQUINA, Nelson. Jornalismo: questões, teorias e "estórias". Lisboa: Veja, 1999.

UNESCO. A Declaração da Unesco para os Media. 1983.

WELIKSON, Camila. A produção da notícia em ambiente de conflito. 0 caso israelopalestiniano. Dissertação de mestrado em Estudos dos Media e do Jornalismo. Lisboa: Universidade Nova de Lisboa, 2008.

Recebido em: 04/05/2019.

Publicado em: 23/07/2019.

Revista Pauta Geral-Estudos em Jornalismo, Ponta Grossa, vol. 6, n. 1, p. 22-38, Jan/Jun, 2019. 